\title{
MEMÓRIAS DA MORTE E A (TRANS)FORMAÇÃO DE SUA IDENTIDADE NO ROMANCE DE SARAMAGO
}

\author{
Josiele Kaminski Corso Ozelame* \\ Nataly Yolanda Capelari dos Santos ${ }^{* *}$ \\ Universidade Estadual do Oeste do Paraná
}

Resumo: Podemos inferir que somos constituídos de passados, amontoados de situações e acontecimentos que se integram, interagem e se excluem, contribuindo para a formação do "eu" durante o passar do tempo, mediante ações que possuem uma finitude, com a morte. Assim, pois, segundo Candau (2011), o jogo existente entre a memória, resultando na construção da identidade é composto de recordações e olvido. É, portanto, nessa tríade memória-identidade-morte que este artigo se debruça, a fim de, a partir das memórias construídas cultural e socialmente da morte, de "passados", demonstrar como isso contribui para a construção e personificação da personagem principal do romance de José Saramago (2005), As intermitências da morte - a própria morte. Para esse fim, nos propomos, inicialmente, a rememorar e discutir os conceitos de memória e identidade e sua inter-relação a partir de Candau (2011), Hall (2006) e Bauman (2005), além da pré-concepção sobre a morte construída no imaginário humano, figura caricata de um esqueleto envolto em sua foice, tendo como guia os estudos de Elias (2001), Ariès (2017) e Simmel (1998). Em seguida nos atemos à personagem morte e a formação/transformação de sua identidade no romance saramaguiano em busca do seu eu essencial. Finalizamos a pesquisa e consideramos a morte saramaguiana dotada de um sentido reformulado, como essencialidade à vida e geradora da mesma apesar de sua paradoxalidade.

Palavras-chave: Literatura Portuguesa. Morte. Memória. Identidade.

\section{Introdução}

Todos nós, seres humanos, somos constituídos de memórias, as quais definem e modelam o que somos e o que seremos, construindo aquilo que chamamos de identidade. Para

\footnotetext{
(9) (1) Esta obra está licenciada sob uma Creative Commons - Atribuição 4.0

* Doutora em Literatura pela Universidade Federal de Santa Catarina (UFSC). Professora do Curso de Letras e do PPG-Sociedade, Cultura e Fronteiras da Universidade Estadual do Oeste do Paraná - UNIOESTE/Foz do Iguaçu/PR. E-mail: josicorso@gmail.com.

** Mestranda pelo Programa de Pós-Graduação Interdisciplinar em Sociedade, Cultura e Fronteiras pela Universidade Estadual do Oeste do Paraná, campus de Foz do Iguaçu. Bolsista CAPES/. Especialista em Metodologia do Ensino de Língua Portuguesa e Literatura pela FAEL e graduada em Letras Português/Inglês pela Unioeste, Foz do Iguaçu. E-mail: naty.ycs@gmail.com.
} 
que as memórias existam pressupõe-se que haja também uma finitude, uma morte. Esta, não necessariamente necessita ser de um corpo físico, mas pode ser de momentos; um amigo que se vai; um amor que se acaba ou um acontecimento que passou. A morte torna-se, assim, conjetura para o desenvolvimento e surgimento da memória, a qual também é base para a formação da identidade, visto que um indivíduo que se esquece de seu passado, o mata e deixa de saber quem é, quem foi.

Essa tríade torna-se indispensável para o assunto que nos propomos a tratar e que envolve o romance publicado no ano de 2005 pelo português José Saramago. Neste, a morte é uma personagem que adquire traços e características humanas, sofrendo uma profunda crise de identidade que se traduz em sua personificação ao fim da narrativa.

Atendo-se a isto, o artigo visa rememorar alguns conceitos de identidade e memória e sua inter-relação, além da compreensão de morte. Embora os conceitos utilizados sejam aplicados em relação ao ser humano real, transpomô-los para o universo ficcional, considerando que continuarão com a mesma força e sentido devido ao fato da literatura mimetizar a realidade e, portanto, utilizar traços e características tanto dos seres humanos quanto da realidade de modo transformado/modificado na ficção - no romance em análise.

Além disso, nos propomos a demonstrar como a identidade da morte - através de nossas memórias e, inicialmente como entidade - e logo após como personagem é construída e transformada no decorrer da trama, modificando sua identidade na constituição de um novo ser, contudo sem perder sua essência.

\section{Memória, identidade e morte: definições e relações}

Para tratarmos da construção de uma personagem e, portanto, de sua identidade dentro de uma narrativa ou a partir de nossas memórias, torna-se necessário esclarecer brevemente alguns conceitos aplicados neste estudo. Dentre eles, abordamos principalmente as questões da memória, sua relação para a constituição da identidade, sua formação, e a relação da morte no processo de construção das memórias.

Atinente à identidade, podemos dizer que um conceito que era, anteriormente, utilizado para designar as características estáveis de um indivíduo, hoje passa a designar um conjunto de características modeláveis e à sua disposição para ser utilizada em circunstâncias diferenciadas. Em Bauman,

e perguntar "quem você é" só faz sentido se você acredita que possa ser outra coisa além de você mesmo; só se você tem uma escolha, e só se o que você escolhe depende de você; ou seja, só se você tem de fazer alguma coisa para que a escolha seja "real" e se sustente (BAUMAN, 2005, p. 25). 
Se tomarmos essa ideia, consideramos a identidade como algo que pode ser negociado, construído e constantemente modificado - líquido, já que o você pode escolher quem quer ser. Sobre isso, Hall também complementará, afirmando que é característica da pós-modernidade essas identidades fragmentadas, que podem ser selecionadas e descartadas conforme o sujeito deseja:

O sujeito assume identidades diferentes em diferentes momentos, identidades que não são unificadas ao redor de um "eu" coerente. Dentro de nós há identidades contraditórias, empurrando em diferentes direções, de tal modo que nossas identificações estão sendo continuamente deslocadas (HALL, 2006, p. 13).

Relacionada à identidade está a memória. É esta, guardada pelo sujeito que molda e constrói o que ele pode vir a ser. Isso se nota nos casos conhecidos de amnésia, onde o indivíduo que perde a memória perde também a consciência de si, do que é ou do que foi. Como salienta Candau,

\footnotetext{
A memória, ao mesmo tempo em que nos modela, é também por nós modelada. Isso resume perfeitamente a dialética da memória e da identidade que se conjugam, se nutrem mutuamente, se apoiam uma na outra para produzir uma trajetória de vida, uma história, um mito, uma narrativa (CANDAU, 2011, p. 16).
}

Ainda de acordo com o autor, a memória gera a identidade e participa da sua construção, do mesmo modo que a identidade molda algumas características que farão com que o ser humano incorpore alguns aspectos de seu passado, fazendo "escolhas memoriais" (CANDAU, 2011, p. 19). O passado e essas escolhas de memórias passadas só são possíveis na medida em que há uma mediação mortuária. Para que as memórias existam, pressupõe-se, também, a existência da morte de acontecimentos ou momentos, sua perda ou substituição no decorrer do tempo. As memórias são construídas de passados, os quais já não existem, já tiveram sua existência apagada, morta pelo tempo, mas que permanecem na memória.

É também mediante a memória, como Elias (2001) afirma, que se mantém um morto vivo, quando há o rompimento de tudo o que é recordável e rememorável, o sentido de tudo que um determinado povo durante fez de significativo durante muito tempo se extingue.

Um sujeito morto de verdade é aquele do qual ninguém se lembra, aquele que tem sua individualidade apagada com a finitude da vida. Entretanto, é possível continuar a viver e ter sua identidade mantida pela recordação, pela lembrança. Segundo Candau, a memória dos mortos é um recurso essencial para a identidade. Esse trabalho da memória e da identidade que se organiza ao redor dos mortos se manifesta explicitamente nos monumentos cuja etimologia, por outro lado, remete à recordação: sua função é de "instigar, pela emoção, uma memória viva", dar a ver a perenidade e manter assim a "identidade de uma comunidade 
étnica ou religiosa, nacional, tribal ou família” (CANDAU, 2011, p. 145).

\section{Uma construção identitária coletiva de morte}

Dizer que a morte é algo vivenciado em todas as sociedades e culturas, não acrescenta nada a esta discussão. A novidade vem da construção e da incorporação do morrer que é realizado e fixado por cada cultura durante seu desenvolvimento. É a compreensão e apreensão que cada povo faz da morte, de acordo com suas vivências e sua cultura que definirá a relação que tem com finitude da vida e, à medida que esses grupos de pessoas se desenvolvem, também suas acepções sobre os mais diferenciados assuntos se modificará.

Ao tratar sobre os moribundos, o envelhecer e morrer, Elias (2001) chama nossa atenção para as concepções e a ideia de morte, que foram se modificando no decorrer do desenvolvimento humano de acordo com cada cultura. Segundo o sociólogo, é importante saber como as situações envoltas no e com o morrer eram tratadas para entender por que isso se tornou diferente.

Elias (2011) aponta que nas sociedades medievais havia uma maior participação das pessoas nos ritos e processos mortuários. Embora a expectativa de vida desses indivíduos fosse menor, houvesse mais perigos e menos conhecimento médico ou de cura para as doenças, a morte era mais dolorosa para os moribundos.

Se compararmos com nossa sociedade moderna, contrastando à medieval, sabemos como aliviar dores causadas pelas doenças e pelo estado moribundo do indivíduo, além disso, o sentimento de culpa é menor. Entretanto, há um afastamento da família e dos próprios indivíduos com relação aos ritos fúnebres, procuramos afastar a morte de nós ou daqueles próximos através da medicina ou condições saudáveis de vida, recusando proferir a palavra morte.

Essa recusa ou simplesmente a não nomeação morte, como aponta Gomes, advém da propagação do horror numa tentativa de purificação pelo dizível, assim,

\footnotetext{
não apenas se tornava coerente que o moribundo, e a representação explícita e periclitante da morte que ele transportava em seu corpo vegetativo, fosse adequadamente isolado do mundo são, como também devia ser igualmente apartado do dizível, tornando-se inominável o seu estado "real", assim sendo, imoral (GOMES, 2007, p. 194).
}

Nas pesquisas de Ariès (2017) percebemos que em nossa época (a partir do fim do século XX), a morte tornou-se inominável, ou seja, não se pode mais mencionar seu nome e tenta-se superar a morte, mesmo sabendo que todos morrerão: "tecnicamente, admitimos que podemos morrer, fazemos seguro de vida para preservar os nossos da miséria. Mas, realmente, 
no fundo de nós mesmos, sentimo-nos não mortais" (ARIÈS, 2017, p. 98).

Esse temor da morte parece estar mais ligado à perda de uma individualidade do ser humano do que da morte em si, em outras palavras, mais próximo da identidade e do que marca uma memória de um ser na realidade. Quando um ente próximo morre, o que se sente e o que se busca é o não apagamento da sua individualidade, que permanece vivo na memória, através de seus atos e realizações, delimitados também pelo que ele é.

Simmel (1998) assinala que desde o início de seu desenvolvimento o eu está intimamente ligado à vida e é na medida em que vivemos que ele se destacará dos "conteúdos de vida" e se constituirá como uma unidade e continuidade no interior da vida. Segundo ele, a morte surge como para liberar os conteúdos intemporais da vida ao mesmo tempo em que destaca o limite de tudo vivido. É nesse sentido que surge, como salienta o autor, a ideia de imortalidade. Nela o "eu poderia conseguir separar-se inteiramente da contingência dos conteúdos particulares" (SIMMEL, 1998, p. 182).

A morte, então, é vista como a parte negativa do existir que destrói tudo o que um ser construiu ao longo de sua existência. Por não poder explicá-la e não saber exatamente o que a morte traz para quem morre, se há algo após ou não, os homens criaram representações desta, transformando-a numa personagem das histórias e narrativas em geral.

A representação personificada da morte surge, no ocidente, de acordo com Guerreiro (2014), no século XVII, como "um esqueleto envolvido numa longa capa negra, transportando a foice para 'ceifar' a vida, incutindo medo, terror e angústia, sentimentos de aflição que fazem da ideia de Morte uma perseguição fatal a que não se pode escapar" (GUERREIRO, 2014, p. 172). Essa figura intimamente ligada ao terror dos fantasmas e corpo decomposto do humano passa a fazer parte da cultura nacional de diversos países.

Essas culturas, segundo Hall (2006, p. 50), “são compostas não apenas de instituições culturais, mas também de símbolos e representações”, as quais também são construídas a partir de memórias reavivadas "que só os traços-vestígios do pretérito são capazes de provocar" (CATROGA, 2001, p. 48, grifos do autor).

Nesse sentido, portanto, podemos afirmar que esses símbolos e representações envoltos à figura personificada da morte é o que permanece nas memórias dos indivíduos e o que constitui com as diversas re-configurações a identidade e significado dela em várias culturas. É a partir disso, de um imaginário coletivo comum que Saramago partirá para construir um traço característico inicial para sua personagem. 


\section{A morte do romance saramaguiano e a (trans)formação de sua identidade}

No romance, As intermitências da morte, publicado em 2005, a morte assume características de uma personagem-entidade que entra em greve, suspendendo suas atividades por vários meses. A morte é construída tal qual a materializamos na forma de uma imagem esquelética envolta em seu capuz, trazendo na ossatura da mão uma foice, conforme mencionamos acima.

Devido ao medo que as pessoas possuem dela e seu incessante desejo em afastá-la, a morte permite que os seres humanos de um país monarquista não tenham mais suas vidas findadas: todos se tornam imortais. O que inicialmente era magnífico - inicialmente, pois todos os habitantes da cidade viveriam eternamente -, com o passar do tempo torna-se insuportável, até que habitantes daquele país comecem a desejar a morte de si próprios ou de pessoas próximas. Atendendo ao desejo, ela decide avisar aos indivíduos sobre o fim de suas vidas com antecedência de uma semana.

É a partir desse momento que a morte surge, efetivamente, como personagem da narrativa, a qual se concentra em torno das ações, pensamentos e memórias da própria morte na busca da resolução do imprevisto de uma de suas cartas - destinadas a um violoncelista que retorna e, portanto, não tem sua existência extinta.

Saramago constrói essa personagem de tal forma que, mesmo sabendo que se trata de um universo imaginário, de uma construção social da morte e também fíctícia, o leitor consegue se aproximar e se identificar com o sofrimento dela. Isso se deve à forma com que o romancista cria a personagem, sem muitas explicações, tampouco descrições, portanto de modo fragmentado, mas permitindo o acesso aos seus pensamentos e memórias individuais (o que não é possível concretamente, já que o conhecimento que temos do outro é limitado, condicionado aos modos como este fala e age com os demais), conduzindo a perspectiva do leitor para um caminho reverso ao que se espera em relação à morte. O medo e o pânico cedem lugar à compaixão e solidariedade.

Sobre essa fragmentação da personagem que dá a impressão de unicidade pelos pensamentos, Candido (1995, p. 58) discorre que, no plano da técnica da caracterização corresponde ao modo como conhecemos os indivíduos que estão próximos a nós. Entretanto, com uma diferença: na vida real essa visão fragmentária "é imanente à nossa própria experiência" e no romance é o escritor quem dirige e cria essa fragmentação e nele é possível variarmos a interpretação que fazemos da personagem.

Por mais que se trate de uma representação a um ser que não existe concretamente, 
todas as demais descrições são humanas de modo que o narrador parece querer aproximar a morte como a algo natural e familiar, que faz parte da vida:

A morte conhece tudo a nosso respeito, e talvez por isso seja triste. Se é certo que nunca sorri, é só porque lhe faltam os lábios [...] Há quem diga, com humor menos macabro que de mau gosto, que ela leva afivelada uma espécie de sorriso permanente, mas isso não é verdade, o que ela traz à vista é um esgar de sofrimento, porque a recordação do tempo em que tinha boca, e a boca língua, e a língua saliva, a persegue continuamente (SARAMAGO, 2005, p. 136).

Quem poderia imaginar uma morte com recordações se ela parece não ter a mínima compaixão para com os homens quando chega a hora de ceifar-lhes as vidas? Apelar a esses momentos passados demonstra, para Candau (2011), um desafio ao futuro, de modo a avaliar no hoje, o que poderia ter sido feito e o que foi feito, além do que ainda pode ser realizado.

Embora tente fazer um afastamento entre personagem e pessoa, de modo que tampouco ela aceite ser nomeada como Morte, com letra maiúscula, o que o que o escritor consegue é justamente o contrário, pois o leitor acaba se aproximando mais da personagem e sentindo compaixão por ela:

Na tarde deste mesmo dia, como já havíamos antecipado, chegou à redacção do jornal uma carta da morte exigindo, nos termos mais enérgicos, a imediata rectificação do seu nome, senhor director, escrevia, eu não sou a Morte, sou simplesmente morte, a Morte é uma cousa que aos senhores nem por sombras lhes pode passar pela cabeça (SARAMAGO, 2005, p. 109).

Nesse sentido, Candau (2011) explica que o nome próprio ou qualquer nominação genérica de um sujeito ou um grupo de sujeitos é uma maneira de controlar a "alteridade ontológica" desse sujeito ou da alteridade que se representa de um grupo. Neste caso, a diferenciação das mortes através da nomeação com maiúscula e minúscula evidencia o intuito da personagem do romance em não ser comparada a um outro, o qual parece mais assustador e catastrófico do que si própria.

Em seus estudos sobre a atopia do nome próprio, em um capítulo destinado à Saramago e ao presente romance, Gomes (2007) considera que a morte com m minúsculo não se refere àquela "antiga superioridade da "Morte", "monumentalizada, maiusculizada" (GOMES, 2007, p. 190), presente numa sociedade do progresso e da utopia do útil”, mas sim àquela morte marginalizada, obscura, simples. $\mathrm{O}$ estudioso ainda complementa que a morte do romance consegue transformar o lugar nenhum, o vazio, o caos e a ausência em ordem e um lugar, faz da "atopia, um também topos" (GOMES, 2007, p. 191).

Ainda, parafraseando Badiou, citado por Gomes, a única coisa que pode ser subtraída ao nome próprio é o próprio inominável, mas em toda sua singularidade também é o único 
que não possui um nome próprio. O pesquisador questiona se já que o inominável não é nomeado por uma propriedade, então utilizar um adjetivo para a nomeação seria o mesmo que criar uma metáfora ou referência múltipla a este, contudo chega à conclusão que isso não é possível devido à atribuição de valor contido no nome próprio. Mesmo que digamos morte serial killer, o próprio nome morte já contém um valor historicamente construído e propagado que não permite uma metáfora ao mesmo tempo em que a permite.

A morte é humanizada para ser apresentada ao leitor de forma mais coerente e completa, tendo a possibilidade de sentir, mesmo sem coração; de pensar, mesmo sem um cérebro. Essa construção permite (ou não) simpatizar com a personagem e, através da identificação e da aproximação, une os dois mundos - ficcional e real, conforme propõe Rosenfeld:

\begin{abstract}
A personagem é um ser fictício, - expressão que soa como paradoxo. De fato, como pode uma ficção ser? Como pode existir o que não existe? No entanto, a criação literária repousa sobre este paradoxo, e o problema da verossimilhança no romance depende desta possibilidade de um ser fictício, isto é, algo que, sendo uma criação da fantasia, comunica a impressão da mais lídima verdade existencial (ROSENFELD, 1995, p. 55).
\end{abstract}

As características pessoais e físicas, nesse caso, principalmente, o que a morte sente e pensa, suas memórias, o modo como os outros personagens da obra a veem e o que pensam sobre ela resultará no que ela é. Isso também faz com que ela seja, mesmo que já prédeterminada pelo escritor, apreendida com mais completude e força.

Rosenfeld salienta que é justamente pela forma com que o autor conduz a maneira de ver e acompanhar a narrativa, "através de aspectos selecionados de certas situações de aparência física e do comportamento [...] ou diretamente através de aspectos da intimidade das personagens $[\ldots]$ que o autor torna a personagem até certo ponto de novo inesgotável e insondável" (ROSENFELD, 1995, p. 35-36). Assim, além de mimetizar características da morte como entidade, aquela figura esquelética que conhecemos com todas as características a ela atribuídas, a forma como ela é construída no romance (os empasses no qual se envolve, as decisões que toma, o que pensa e como age) a tornam mais grande e permitem tantas compreensões que a personagem, em sua simplicidade de morte com letra minúscula, torna-se complexa e inesgotável.

Além disso, conforme Candau,

uma vez que os quadros sociais da memória orientam toda evocação, a anamnese de todo indivíduo dependerá daqueles que lhe são contemporâneos: ele oferecerá, portanto, uma visão dos acontecimentos passados em parte transformada pelo presente ou, mais exatamente, pela posição que ele próprio ocupa nesse presente 
(CANDAU, 2011, p. 75).

Saramago, primeiramente, descreve o que todos já conhecem sobre a morte. Sua identidade é baseada em uma descrição previamente concebida e culturalmente construída pelas pessoas, de que é algo terrível, que chega sem hora e deixa os indivíduos próximos ao falecido tristes, sozinhos, com medo.

A característica emotiva da morte solidifica-se quando o escritor afirma que ela, a pobre “coitada da morte" (SARAMAGO, 2005, p. 140), não pôde escolher seu destino, que é morte apenas por obrigação, pois já não se lembra de quando the foi passado o ofício, e, pela habitualidade do mesmo, acaba fazendo as coisas automaticamente, assim como os humanos fazem no seu dia-a-dia quando o serviço já lhe é conhecido e sem novidades.

Para Gomes, ela "se torna significativa quando deixa de ser o impensável, o puro inominável, e passa, como nesta ficção, a não ser nada, ou, não ser mais nada. Neste instante, desmascara-se o que há de hipocrisia na morte inominável, do silêncio estratégico e respeitoso" (GOMES, 2007, p. 191).

Isso nos direciona para Candau, quando discorre acerca da relação da memória humana com o passado. Do mesmo modo que nós mantemos conflitos entre o que um dia fomos e como fomos, com lados obscuros e radiantes, fazemos rejeições e adesões, e escolhas entre um lado bom e outro que consideramos ruim de tudo que já fizemos, de nosso passado para modificar o que somos hoje e o que poderemos modificar desse hoje, amanhã. Assim, a morte da narrativa, bem como o leitor são levados a contrastar o passado e o presente na formulação de um futuro.

É mais do que compreensível a perplexidade da morte. Tinham-na posto neste mundo há tanto tempo que já não consegue recordar-se de quem foi que recebeu as instruções indispensáveis ao regular desempenho da operação de que a incumbiam. Puseram-lhe o regulamento nas mãos, apontaram-lhe a palavra matarás como único farol das suas actividades futuras e, sem que provavelmente se tivessem apercebido da macabra ironia, disseram-lhe que fosse à sua vida (SARAMAGO, 2005, p. 158159).

É notório também que o sentimento anterior de liquidar com a vida do violoncelista é posto em dúvida. Em seu interior, a morte já não o quer matar. Isso se torna mais perceptível porque o escritor passa a utilizar pronome possessivo para referir-se ao músico. $\mathrm{O}$ entendimento é que o "seu" não significa apenas que o homem era o único que não havia morrido, mas algo mais além: “Aquele é o seu homem, um músico" (SARAMAGO, 2005, p. 165); "A morte está orgulhosa do bem que o seu violoncelista tocou" (SARAMAGO, 2005, p. 167). Esse "além" subentendido nas entrelinhas sugere que o homem passa a ter um 
significado a mais para a morte, mais erotizado.

A morte em conflito com seu eu anterior, presente e um possível eu futuro busca uma identidade para se apegar e, "uma vez que a identidade muda de acordo com a forma como o sujeito é interpelado ou representado, a identificação não é automática, mas pode ser ganhada ou perdida" (HALL, 2006, p. 21), neste caso pelo leitor que pode aceitar a transformação ou não.

Após observar o homem por alguns dias, a morte decidiu resolver a situação. Solicitou à gadanha que entregasse as cartas por, no máximo, três dias, que ela as deixaria já escritas. Saiu por uma porta nunca utilizada e voltou como mulher, disposta a conhecer o violoncelista e entregar a carta avisando-lhe de seu destino: "Estou irresistível, confessa, Depende do tipo de homem a quem queiras seduzir, Em todo o caso parece-te mesmo que vou bonita, Fui eu quem o disse em primeiro lugar, sendo assim, adeus, estarei de regresso no domingo" (SARAMAGO, 2005, p. 182).

A morte constrói sua própria identidade mediante escolhas, alternativas e lutas entre suas identidades conflituosas - recordações antes-morte/ morte-ceifadora/ morte-soberana/ mulher - e luta para proteger e manter algo novo:

A "identidade" só nos é revelada como algo a ser inventado, e não descoberto; como alvo de um esforço, "um objetivo"; como uma coisa que ainda se precisa construir a partir do zero ou escolher entre alternativas e então lutar por ela e protegê-la lutando ainda mais - mesmo que, para que essa luta seja vitoriosa, a verdade sobre a condição precária e eternamente inconclusa da identidade deva ser, e tenda a ser, suprimida e laboriosamente oculta (BAUMAN, 2005, p. 21-22).

Relacionamos ao excerto acima de Bauman à tentativa da morte e também do autornarrador do romance, a todo o momento, em reiventar a identidade da morte, construí-la a partir da junção de vários momentos e acontecimentos que se integram e vão formando alguma coisa maior.

\section{Considerações}

Somos seres constituídos e construídos de passados. Tudo aquilo pelo que passamos, as experiências, os momentos e as recordações se integram e moldam o eu, dispõem os degraus para a escada do que podemos vir a ser. Contudo, no entremeio do caminho, influenciados e sofrendo interferências de nossa cultura, sociedade e, principalmente, do outro podemos modificar e des-construir identidades.

Esse jogo do passado permance vivo, no ser humano, pela memória, a qual desempenha, como demonstramos no decorrer do artigo, papel fundamental e intrínseco na 
formação do eu. Permeando esses dois aspectos temos a finitude ou morte, pois memórias são lembranças ou esquecimentos de momentos mortos, que tiveram sua finalização em algum período da vida.

A morte, nosso tema de análise, caracteriza-se por seu paradoxo ou contrário: fim da vida. Dependedo da relação que o indivíduo e a cultura da qual faz parte estabelecem com ela, definirá o conceito e as formas como cada qual lidará com um acontecimento tão natural e assustador ao mesmo tempo. Por esse motivo, verificamos culturas nas quais a morte é festejada e outras que a refutam, tais quais grande parte do mundo ocidental, conforme exposto.

É, pois, deste assunto que apresenta tão poucas respostas e por isso, causa tanto temor, que José Saramago se aproveita, no romance, com grande ironia e humor para reformular a compreensão de morte possuída pelos indivíduos contemporâneos. Essa (des)construção constante envolve, assim, o ser da morte para nós (estabelecido por nossos passados e memórias), que se traduz no ser da personagem fictícia principal: a esquelética e assassina morte (o que esta é e o que virá a ser).

Na ficção os múltiplos olhares do narrador que se confundem e se misturam com a interpretação do leitor na organização do sentido do romance, demonstrando uma sociedade modificada, na qual também as personagens não sabem ao certo quem são, e estão em constante busca e luta para definir, construir ou transformar suas identidades.

A construção cultural que o ocidente possui da morte como um ser esquelético, assustador e que destrói a vida como um todo do futuro morto e dos que estão próximos, parte de memórias de nosso passado que urgem o tempo todo numa dialética de modelação e remodelação da identidade e das próprias memórias que possuímos acerca da morte. Isso é representado com magnitude, ironia e excelência por José Saramago, o qual transforma uma ideia já enraizada sobre algo tão grande como a identidade da morte, em algo mais suave e natural como uma necessidade intrínseca à vida.

Saramago ressalta o que Simmel (1998), Elias (2001) e diversos outros estudiosos afirmaram sobre a morte: que ela é essencial à vida. Contudo, o escritor português faz isso mediante uma metáfora narrativa. A morte morre como ser assustador e renasce, assim como a fênix, como um ser humano, uma mulher, aquela que é geradora da vida.

Ela o faz, portanto, mediante jogos, escolhas e refutações de características e construções sociais, demonstrando o conflito entre o que os outros construíram e definiram de si para aquilo que ela definitivamente é ou gostaria de ser. É, então, neste aspecto que a 
metáfora da morte se traduz pela personificação: o que era temeroso e assustador é (trans)formado em algo digno de alegria, o gerar de uma vida. Graças à morte existem novas vidas, pois do contrário, não haveria sentido em um nascer se todos possuíssem vida eterna.

\section{Referências}

ARIÈS, Philippe. História da morte no Ocidente: da Idade Média aos nossos dias. Trad. de Priscila Viana de Siqueira. - [Ed. especial]. - Rio de Janeiro: Nova Fronteira, 2017. (Coleção Clássico para Todos).

BAUMAN, Zygmunt. Identidade: entrevista a Benedetto Vecchi. Trad. de Carlos Alberto Medeiros. Rio de Janeiro: Jorge Zahar, 2005.

CANDAU, Joel. Memória e identidade. Trad. de Maria Leticia Ferreira. São Paulo: Contexto, 2011.

CANDIDO, Antonio (Org.). A personagem do romance. In: . A personagem de ficção.

9. ed. São Paulo: Perspectiva, 1995, p. 53-80.

CATROGA, Fernando. Memória e história. In: PESAVENTO, Sandra Jatahy (Org.). Fronteiras do milênio. Porto Alegre: UFRGS, 2001, p. 43-69.

ELIAS, Norbert. A solidão dos moribundos, seguido de, envelhecer e morrer. Trad. de Plínio Dentzien. Rio de Janeiro: Jorge Zahar, 2001.

GOMES, Daniel de Oliveira. Nome próprio, a dimensão Atópica da escritura. 2007. 228 p. Tese (Doutorado em Literatura) - Universidade Federal de Santa Catarina. Florianópolis, 2007.

GUERREIRO, Emanuel. A ideia de morte - do medo à libertação. Diacrítica, Braga, v. 28, n. 2, p. 169-197, 2014. Disponível em: https://www.researchgate.net/profile/Antonio_Roazzi/publication/292134453_A_morte_e_su as_imagens/links/56a94acd08aef6e05df2a61b/A-morte-e-suas-imagens.pdf. Acesso em: $17 / 01 / 2018$.

HALL, Stuart. A identidade cultural na pós-modernidade. Trad. de Tomaz Tadeu da Silva e Guacira Lopes Louro. 11. ed. Rio de Janeiro: DP\&A, 2006.

ROSENFELD, Anatol. Literatura e personagem. In: CANDIDO, Antonio (Org.) et al. $A$ personagem de ficção. 9. ed. São Paulo: Perspectiva, 1995, p. 11-49.

SARAMAGO, José. As intermitências da morte. São Paulo: Companhia das Letras, 2005.

SIMMEL, Georg. A Metafísica da Morte. Política \& Trabalho, Paraíba, n. 14 - Setembro, p. 177-182, 1998. Trad. de Simone Carneiro Maldonado. Disponível em: http://www.oocities.org/collegepark/library/8429/14-simmel-1.html. Acesso em: 15/09/2017. 


\section{Death's memories and the (trans) formation of its identity in Saramago's novel}

Abstract: We are constituted by pasts, heaps of situations and events that integrate, interact and exclude themselves, contributing to a formation of "what we are" trhough the time, through actions that have a finitude, a death. Thus, according to Candau (2011), the game wich exists in memory, resulting in the construction of identity and composed of memories and oblivion. It is, therefore, in this memory-identity-death triad that this article studies, in order to, from the cultural and socially constructed memories of death, of "past", we aim to demonstrate how this contributes to the construction and personification of the main character of the José Saramago's novel (2005), Death with interruptions - death itself. To this end, we propose, initially, to remeber and discuss the concepts of memory and identity and their interrelationship from Candau (2011), Hall (2006) and Bauman (2005), as well as the preconception about death built in the human imagination - a caricature of a skeleton wrapped in his scythe -, guided by the studies of Elias (2001), Ariès (2011) and Simmel (1998). Then we attach to the character death and the formation / transformation of his identity in the saramaguian novel in search of its essential self. We conclude the research and consider death composed by a reformulated sense, as essential to life and the source of life despite its paradox.

Keywords: Portuguese Literature. Death. Memory. Identity.

Recebido em: 05/02/2018

Aceito em: 15/02/2018

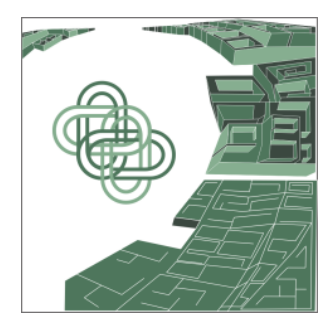

